\title{
PERCEPÇÃO DO CLIMA DE SEGURANÇA PELA EQUIPE DE ENFERMAGEM EM UM HOSPITAL ESPECIALIZADO EM SAÚDE DA MULHER
}

\author{
Beatriz Magalhães Fernandes (IC), Marcia Raquel Panunto (PG), Daniela Fernanda dos Santos \\ Alves(PG), Edinêis de Brito Guirardello (PQ)
}

\section{Resumo}

O clima de segurança é uma das formas de medir a cultura de segurança e esta pesquisa teve como objetivo avaliar a percepção da equipe de enfermagem sobre este aspecto. Estudo transversal realizado em um hospital de ensino especializado com 112 profissionais de enfermagem. Os resultados apontaram uma baixa percepção dos profissionais quanto a presença de atitudes que favorecem a segurança do paciente, exceto para a satisfação no trabalho.

Palavras Chave: Segurança do paciente, Enfermagem, Ambiente de instituições de saúde.

\section{Introdução}

O clima de segurança é uma medida temporal da cultura de segurança, podendo ser avaliado pelas percepções individuais sobre as atitudes e iniciativas da instituição quanto ao seu comprometimento com as questões da segurança do paciente em ambientes hospitalares ${ }^{1-3}$. Objetivos: avaliar a percepção do clima de segurança pela equipe de enfermagem em um hospital especializado em saúde da mulher.

Método: trata-se de um estudo transversal, descritivo, realizado em um hospital de ensino especializado, no interior do Estado de São Paulo, com 112 enfermeiros, técnicos e auxiliares de enfermagem, envolvidos na assistência direta aos pacientes, com tempo de experiência igual ou superior a seis meses. Foram excluídos os profissionais de enfermagem que exerciam atividades gerenciais e que estavam em férias, afastamentos ou licença saúde. Para a coleta de dados foram utilizados uma ficha de caracterização pessoal e profissional e o Safety Attitudes Questionnaire - Short Form 2006.

\section{Resultados e Discussão}

O clima de segurança é percebido como favorável a segurança do paciente por 50\% dos profissionais e destes $75 \%$ estão satisfeitos com o trabalho. Apenas um em cada quatro profissionais aprova as iniciativas da gestão do hospital e da unidade para a segurança do paciente.
Tabela 1. Média, desvio-padrão, mínimo, máximo e quartis dos escores das subescalas do SAQShort form 2006. Campinas, SP, 2015.

\begin{tabular}{lcccccccc}
\hline \multicolumn{1}{c}{ SAQ } & $\mathrm{n}$ & Média & $\begin{array}{c}\text { Desvio- } \\
\text { padrão }\end{array}$ & Minimo & Q1 & Mediana & Q3 & Máximo \\
\hline Clima de trabalho em equipe & 66 & 66,1 & 32,5 & 0,0 & 25,0 & 75,0 & 100,0 & 100,0 \\
Clima de segurança & 66 & 63,6 & 34,8 & 0,0 & 25,0 & 75,0 & 100,0 & 100,0 \\
Satisfaçãono trabalho & 66 & 82,1 & 25,6 & 0,0 & 75,0 & 100,0 & 100,0 & 100,0 \\
Reconhecimento do estresse & 99 & 69,5 & 37,1 & 0,0 & 50,0 & 75,0 & 100,0 & 100,0 \\
Percepção da gestão da unidade & 66 & 56,4 & 35,2 & 0,0 & 25,0 & 75,0 & 75,0 & 100,0 \\
Percepção da gestão do hospital & 66 & 53,6 & 34,6 & 0,0 & 25,0 & 50,0 & 75,0 & 100,0 \\
Condições de trabalho & 66 & 65,2 & 31,3 & 0,0 & 50,0 & 75,0 & 100,0 & 100,0 \\
Comportamento seguro & 66 & 60,2 & 30,8 & 0,0 & 25,0 & 75,0 & 75,0 & 100,0 \\
\hline
\end{tabular}

\section{Conclusões}

Os domínios avaliados pelo Safety Attitudes Questionnaire - Short Form 2006 indicam que o clima é favorável a segurança do paciente apenas em relação a satisfação dos profissionais de enfermagem. Resultados desse estudo poderão ser utilizados pelos gerentes de enfermagem para adoção de medidas que favoreçam a assistência segura ao paciente.

\section{Agradecimentos}

Ao local do estudo pela autorização para a execução da pesquisa.

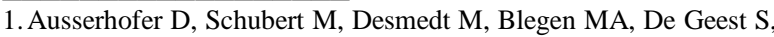
Schwendimann R. The association of patient safety climate and nurse-related organizational factors with selected patient outcomes: a cross-sectional survey. International Journal of Nursing Studies 2013; 50(2): 240-52.

2. Carvalho REFL, Cassiani SHB. Cross-cultural adaptation of the Safety Attitudes Questionnaire-Short Form 2006 for Brazil. Revista Latino-Americana de Enfermagem 2012; 20(3): 575-82.

3. Sexton J, Helmreich R, Neilands T, Rowan K, Vella K, Boyden J et al. The Safety Attitudes Questionnaire: psychometric properties, benchmarking data, and emerging research. BMC Health Services Research 2006; 6(44):1-10.
} 